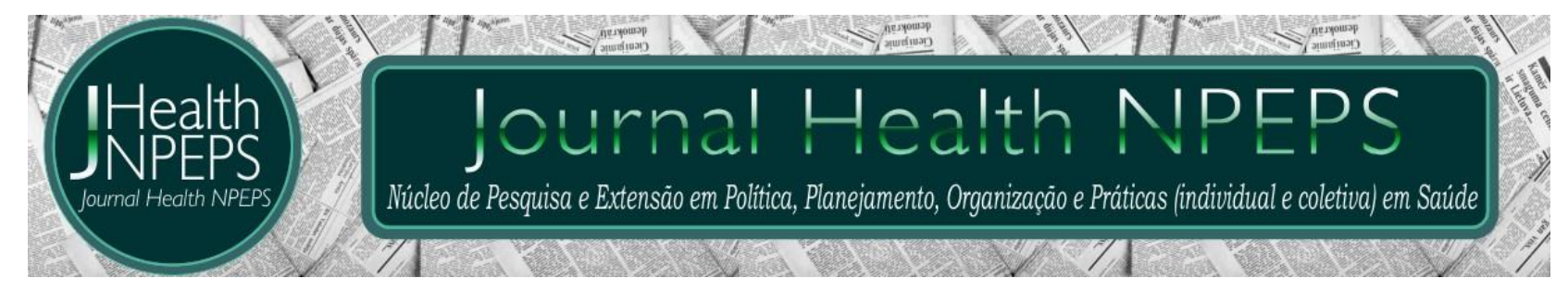

http://dx.doi.org/10.30681/252610103255

ARTIGO ORIGINAL

\title{
Alcoolismo e comorbidades em mulheres
}

Alcoholism and comorbidities in women

Alcoholismo y comorbilidad en mujeres

\section{Brianne Ponce de Leon Sá e Luna ${ }^{1}$, Gildécio Luiz Silva Júnior², Izete Soares da Silva Dantas Pereira ${ }^{3}$}

\section{RESUMO}

Objetivo: identificar as comorbidades relatadas pelas mulheres que frequentam o grupo de Alcoólicos Anônimos do município de Mossoró, Rio Grande do Norte, decorrentes do consumo de bebidas alcoólicas. Método: trata-se de uma pesquisa exploratória, de abordagem qualitativa e corte transversal, a partir de entrevistas estruturadas com oito mulheres frequentadoras do grupo Alcoólicos Anônimos. 0 estudo teve a aprovação do comitê de ética em pesquisa com seres humanos. Resultados: os resultados mostraram que o início do hábito de beber se deu ainda na adolescência, a partir dos 12 anos. Há muitas comorbidades associadas ao consumo de álcool, físicas, psiquiátricas e sociais. Todas as entrevistadas tentaram sozinhas parar de beber, mas não conseguiram. A sobriedade só tem sido possível a partir do apoio do grupo dos Alcoólicos Anônimos, muito embora registrem algumas recaídas. Considerações finais: há necessidade de incrementar estudos sobre a temática, incluindo o gênero feminino como uma importante variável a ser considerada nas políticas públicas de enfrentamento e combate ao alcoolismo e nas estratégias de prevenção e/ou tratamento.

Descritores: Alcoolismo; Comorbidades; Mulheres.

\section{ABSTRACT}

Objective: to identify the comorbidities reported by the women attending the Alcoholics Anonymous group in the municipality of Mossoró, Rio Grande do Norte, resulting from the consumption of alcoholic beverages. Method: this was an

\footnotetext{
${ }^{1}$ Acadêmica do curso de Medicina. Universidade do Estado do Rio Grande do Norte-UERN. Mossoró, Rio Grande de Norte, Brasil. E-mail: bri.ponce@hotmail.com ORCID ID: http://orcid.org/0000-0003-3735-7567 Autor principal Endereço para correspondência: Rua Atirador Miguel Antônio da Silva Neto, s/n, Aeroporto, CEP 59607-360 - Mossoró/RN, Brasil.

${ }^{2}$ Acadêmico do curso de Medicina. Universidade do Estado do Rio Grande do Norte-UERN. Mossoró, Rio Grande de Norte, Brasil. E-mail: gildeciolsjunior@gmail.com ORCID ID: http://orcid.org/0000-0002-6258-7762

${ }^{3}$ Assistente Social. Doutora em Saúde Pública. Docente do Curso de Medicina. Universidade do Estado do Rio Grande do Norte (UERN). Mossoró, Rio Grande de Norte, Brasil. E-mail: izetedantas@hotmail.com ORCID ID: http://orcid.org/0000-0002-2239-6582
} que a publicação original seja corretamente citada. 
exploratory, qualitative and cross-sectional study, based on a structured interview with eight women attending the Alcoholics Anonymous Group. The study was approved by the ethics committee in humans research. Results: it was shown that the beginning of the drinking habit occurred as early as the adolescence, from the age of 12 years on. There are many comorbidities associated with alcohol consumption: physical, psychiatric and social. All the interviewees tried alone to stop drinking, but they failed. Sobriety has only been possible along with the support of the Alcoholics Anonymous group, even though it has shown some members' relapses. Final considerations: there is a need to increase studies on the theme, and include the feminine gender as an important variable to be considered in public policies for coping and combating alcoholism and in prevention and/or treatment strategies.

Descriptors: Alcoholism; Comorbidities; Women.

\section{RESUMEN}

Objetivo: identificar las comorbilidades reportadas por las mujeres que asisten al grupo alcohólicos anónimos en el municipio de Mossoró, Rio Grande do Norte, causado por el consumo de bebidas alcohólicas. Se buscó identificar el perfil sociodemográfica de estas mujeres y comparar las comorbilidades reportadas con lo indicado en la bibliografía sobre el consumo de alcohol. Método: se trata de un estudio exploratorio, cualitativo y transversal, basado en una entrevista estructurada con ocho mujeres que asisten al grupo Alcoolicos Anonimos. el estudio fue aprobado por el comité de ética en investigación con humanos. Resultados: los resultados mostraron que el inicio del hábito de beber comenzó, incluso en la adolescencia, a partir de los 12 años. Hay muchas comorbilidades asociadas al consumo de alcohol: física, psiquiátrica y social. Todos los entrevistados intentaron solos dejar de beber, pero fracasaron. La sobriedad sólo ha sido posible desde el apoyo del grupo de alcohólicos anónimos, aunque registra algunas recaídas. Consideraciones finales: es necesario aumentar los estudios sobre el tema, incluyendo el género femenino como una variable importante a considerar en las políticas públicas para afrontar y combatir el alcoholismo y en las estrategias de prevención y/o tratamiento.

Descriptores: Alcoholismo; Comorbilidades; Mujeres.

\section{INTRODUÇÃO}

O alcoolismo é caracterizado pelo uso abusivo de bebidas alcoólicas, inserido como doença no Código Internacional de Doenças (CID) como Q86. É uma questão de saúde pública que vem preocupando todas as nações, inclusive o Brasil, levando o alcoolismo a ser responsável por causa direta e indireta de morbimortalidades. Seu abuso acarreta problemas familiares e profissionais, debilidades no organismo, gera preconceito, que leva ao isolamento e maior consumo de drogas ${ }^{1-}$ 3.

O alcoolismo, também denominado Síndrome de Dependência do Álcool (SDA), é considerada uma doença multifatorial, que se detecta, quase sempre, numa fase já tardia, devido ao seu curso insidioso e 
prolongado. Os valores, as crenças, as atitudes, influenciam a percepção de cada pessoa acerca da situação, o que poderá interferir diretamente na forma como esta vê, reflete, julga e assimila toda a informação, podendo, assim, por vezes, dificultar o tratamento e consequentemente a qualidade de vida. 0 álcool se constitui na principal substância de abuso experimentada, mundialmente, pela maioria dos indivíduos e em uso cotidiano, durante grande parte da vida, por uma porcentagem considerável de pessoas ${ }^{2,4}$.

Em 2012, foi realizado o II Levantamento Nacional de Álcool e Drogas (Lenad), que estimou que 11,7 milhões de pessoas sejam dependentes de álcool no país. Quando diferenciada a ingestão de bebidas entre homens e mulheres, o percentual dos que consomem álcool com frequência entre os homens subiu de $56 \%$ para $64 \%$, e entre mulheres de 29\% para 39\% da primeira para a segunda análise ${ }^{3}$.

O álcool apresenta maior impacto com consequências mais negativas no organismo feminino do que no organismo masculino, tais como complicações físicas, psicológicos e psiquiátricos: traumas, violência doméstica, quedas, neoplasias, doenças sexualmente transmissíveis, cirrose Journal Health NPEPS. 2019 jan-jun; 4(1):62-79. hepática, mortes no trânsito, suicídios, desentendimentos familiares e afetivos, sendo, também, associado a homicídios, violências, abandono do trabalho, agressividade, doenças cardíacas e cerebrovasculares, entre outros ${ }^{2-6}$.

Desde que a mulher, após seu movimento de emancipação, ampliou seu espaço social, aumentou sua participação na disputa pelo mercado de trabalho, suas responsabilidades de mãe, esposa, dona de casa, provedora e profissional, além de outras, ocorreu uma modificação nos tipos e na gravidade das doenças que incidem sobre o sexo feminino. Doenças como o infarto do miocárdio, acidente vascular cerebral e outras mais frequentes no sexo masculino estão também incidindo de forma mais direta sobre as mulheres. As mulheres estão, cada vez mais, usando drogas lícitas e ilícitas, como: cigarro, álcool, antidepressivos, hipnóticos, ansiolíticos, maconha e cocaína entre outras. Aspectos socioculturais também influenciam de forma particular no padrão de consumo de álcool entre as mulheres ${ }^{4,5}$.

Uma das práticas que propõem a recuperação de alcoolistas, não vinculada à medicina, são os chamados Alcoólicos Anônimos (AA). Este grupo de ajuda mútua exerce impacto 
significativo sobre a reconstrução da pessoa, através da construção gradual de sua identificação como indivíduo-doente, e do alcoolismo como doença. Seu modelo terapêutico está galgado na busca pela sobriedade baseado numa tríade: dar/receber/retribuir, que muitas vezes não é alcançada pela pessoa antes de seu ingresso no $A A$, devido à sociabilidade que 0 álcool proporciona inerente às convivências sociais, mas que pode se tornar um agente de dissociação gerando ruptura de laços familiares, profissionais e sociais. Essa estratégia terapêutica tem possibilitado a recuperação através do resgate de sua responsabilidade fisica e moral, permitindo ressignificar os seus espaços de sociabilidade como a casa e o local de trabalho espaços das relaçoes familiares e profissionais, que são agora valorizadas pela pessoa em recuperação ${ }^{7}$.

O alcoolismo é o conjunto de problemas relacionados ao consumo excessivo e prolongado do álcool. É entendido como o vício de ingestão excessiva e regular de bebidas alcoólicas e todas as consequências decorrentes, sendo uma importante questão de saúde pública, pois além do uso de álcool entre as mulheres estar aumentando crescentemente, este pode ter graves Journal Health NPEPS. 2019 jan-jun; 4(1):62-79. consequências à saúde das mães e a dos recém-nascidos ${ }^{8-12}$.

A literatura tem apontado alguns fatores que podem estar envolvidos no aumento de consumo de álcool entre o gênero feminino, os quais parecem estar relacionados às mudanças no contexto da vida da mulher, seu papel social e ampliação de atividades e responsabiidades. Esse crescimento está associado às mudanças de comportamento social e à entrada da mulher no mercado de trabalho, na vida política. Há uma predisposição para o uso e abuso do álcool e uma tendência ao alcoolismo feminino. Muitas mulheres casadas começam a beber na meia idade, quando seu papel de mãe e esposa é desafiado pela partida de seus filhos, Síndrome do ninho vazio, dissolução do casamento, aposentadoria, entre outros fatores ${ }^{13-16}$.

Vários estudos mostram que as mulheres bebem como forma de se livrar dos sintomas associados a quadros de depressão. As mulheres apresentam sintomas associados à doença como conflitos familiares, ansiedade, depressão e problemas socioeconômicos. O fenômeno do uso de álcool entre as mulheres preocupa por vários motivos, pois a mulher é mais vulnerável ao álcool e tem problemas mais cedo. Visto como 
um comportamento não adequado do ser feminino, que é focalizado pelos atributos como docilidade, fragilidade, afetividade, representando,portanto, ainda um desafio para maiores avanços na área de tratamento ${ }^{4,7,10,16-18 .}$

Alguns fatores como a constituição física e as experiências emocionais da mulher, em suas relações familiares e sociais, contribuem para deixá-la mais vulnerável ao alcoolismo. As influências culturais reforçam ou estabelecem os padrões familiares, a predileção pelo abuso do álcool como o meio de obter alívio da ansiedade e da depressão. Experiências posteriores de privação do apoio emocional podem agir, às vezes, repetitivamente, como precipitantes de períodos de etilismo ou do retorno ao álcool, por parte daquelas que abandonaram o hábito. As usuárias de álcool também sofrem mais riscos de desenvolver doenças cardiovasculares, câncer da mama, osteoporose e distúrbios psiquiátricos, entre outros ${ }^{19-21}$.

$\mathrm{O}$ aumento do consumo de álcool entre as mulheres tem sido encontrado em vários estudos que também apontam para uma maior prevalência de transtornos de personalidade coexistentes, depressivos, transtornos de ansiedade, além de abuso de benzodiazepínicos e barbitúricos. Em Journal Health NPEPS. 2019 jan-jun; 4(1):62-79. decorrência do baixo percentual de pacientes do sexo feminino que acessam e aderem ao tratamento constata-se a necessidade de diferenciar a assistência ao público feminino devido às dificuldades encontradas em participar de um programa em que o predomínio é de indivíduos do sexo masculino 3 ,7, 21-23.

A pesquisa teve como objetivo identificar as comorbidades relatadas pelas mulheres que frequentam o grupo de AA do município de Mossoró, Rio Grande do Norte, decorrentes do consumo de bebidas alcoólicas, comparando-as com o que é apontado na literatura sobre consumo do álcool por mulheres. Além disso, buscou-se identificar o perfil sociodemográfico das mulheres participantes do estudo.

\section{METODO}

Tratou-se de um estudo exploratório, transversal de abordagem qualitativa $^{24}$ realizado com oito mulheres do Grupo de AA de Mossoró (RN), Brasil, no período compreendido entre agosto de 2016 e julho de 2017. A amostra se deu de forma intencional, pois, o número de mulheres era pequeno. Foi informado, nos contatos iniciais para coleta dos dados, que se tratava de vinte mulheres participantes 
das reuniões do AA. No entanto, no período da coleta apenas oito frequentavam com regularidade e se dispuseram a participar do estudo.

A coleta dos dados se deu através de entrevista estruturada, realizada no espaço físico do $A A$, Unidade Centro de Mossoró em sala fechada, bem iluminada com condições de acomodação satisfatórias, antes ou depois das reuniões, à escolha das participantes e após a assinatura do Termo de Consentimento Livre e Esclarecido (TCLE). Antes de iniciar a entrevista as mulheres foram informadas dos objetivos da pesquisa e de seus direitos à indenização e ao ressarcimento, caso fosse necessário. As entrevistas foram realizadas, individualmente, sem uso do gravador para não constranger as entrevistadas de forma que entrevistador e entrevistada pudessem conversar sem a presença de terceiros, garantindo assim um clima de confiança e empatia, segundo os princípios do anonimato, privacidade, sigilo e confidencialidade.

$O$ registro das respostas foi feito pelo entrevistador, considerando que em alguns casos as participantes tinham dificuldade de escrever as respostas, dado o baixo nível de escolaridade e de compreensão das perguntas. 0 preenchimento deste se deu, sem qualquer tipo de identificação nominal, da participante. Para facilitar 0 reconhecimento das respostas e preservar o anonimato foi atribuído, a denominação de flores às entrevistadas: Rosa, Margarida, Órquidea, Azaléa, Violeta, Gerbera, Tulipa e Alfazema.

Com a transcrição das entrevistas, aplicou-se os passos previstos pela análise temática: a) Préanálise, que consistiu na seleção do material de análise, relacionando-os aos objetivos propostos pela pesquisa; b) Exploração do material, onde buscou-se a compreensão do texto através da exploração, com posterior codificação; e c) Tratamento dos resultados obtidos e a interpretação.

A pesquisa foi autorizada pelo Comitê de Ética em Pesquisa (CEP) da Universidade do Estado do Rio Grande do Norte (UERN), sob o número CAAE 49694715.3.0000.5294 em 11 de dezembro de 2015, respeitando as Normas referentes à pesquisa com seres humanos, especificamente a Resolução 466/12 do Conselho Nacional de Saúde (CNS).

\section{RESULTADOS E DISCUSSÃO}


Os resultados obtidos a partir das entrevistas realizadas apontam aspectos relevantes para o conhecimento do perfil das participantes do estudo e das comorbidades encontradas auxiliando na identificação dos malefícios do álcool no organismo feminino, aspecto esse já consensual entre os estudos citados $9,16,25$ 27.

$\mathrm{O}$ perfil identificado mostrou que as mulheres têm idades compreendidas entre 34 a 65 anos. O estado civil se configurou como viúvas, majoritariamente, e as demais solteiras e casadas de forma igual do ponto de vista estatístico. Em relação ao item cor/raça/etnia, a maioria das entrevistadas, autodeclararam-se pardas e as demais, brancas. Dessas, a maioria, seis são procedentes de Mossoró e as restantes de outras localidades do interior do estado do Rio Grande do Norte.

Quanto ao grau de escolaridade, verificou-se que duas não possuem escolaridade, duas apresentaram ensino fundamental incompleto, duas ensino médio incompleto e duas ensino médio completo. As mais variadas profissões foram relatadas no estudo: professora, autônoma, costureira, do lar, aposentada. A renda oscilou entre um a seis salários mínimos. Quanto à religião seis entrevistadas se declararam católicas e duas protestantes evangélicas.

No que tange às comorbidades, foram encontrados diversos problemas associados ao uso do álcool no organismo feminino, tais como: distúrbios hepáticos, transtornos neurológicos e psiquiátricos, síndrome de abstinência e prejuízos no sono, entre outras que interferiam diretamente na saúde desse grupo e afetaram a sua qualidade de vida.

A maioria das mulheres entrevistadas iniciou o consumo de álcool de forma bastante precoce entre 12 e 16 anos de idade, o que confirma outras fontes pesquisadas no Brasil que mostram que muitas mulheres começam a fazer uso de álcool precocemente, ainda na adolescência ${ }^{3,4}$.

A maioria iniciou a ingesta alcoólica nessa fase da vida com o intuito de vivenciar situações prazerosas ou evitar o desprazer. Essas mulheres passaram por diversas experiências, as quais traziam a marca da solidão, da dor, do sofrimento, da vergonha e da discriminação e vivenciaram perdas, agravos físicos e psicológicos decorrentes do uso abusivo de álcool. Além desses motivos, as mulheres ainda relatavam que o uso do álcool ocorreu 
por gostar do sabor da bebida. Os principais fatores de riscos que colaboraram para o início do consumo de álcool em jovens são a curiosidade, a pressão do grupo social, o modelo familiar, a propaganda e a falta de políticas públicas de prevenção Isso vai ao encontro da pesquisa, haja vista que a maioria das mulheres iniciou o uso do álcool em sua própria casa com seus familiares, demonstrando que o beber em locais privados pode ser uma particularidade das mulheres que consomem abusivamente o álcool.

Comecei a beber com 12 anos e não conseguia parar. Eu tinha que beber até cair. Eu tinha muito medo da palavra alcoólatra, ela tem um peso e assusta. (Rosa)

Comecei a beber com 12 anos, na praia com minha tia por incentivo dela. Eu queria beber água e ela me dava cerveja, por isso que tomei a primeira vez. (Margarida)

Comecei com 16 anos, com meus amigos nas festas. Gostava do gosto da cachaça. Se eu fosse para festa todo dia, todo dia eu bebia. Bebia uns quatro copinhos, mais de noite. Ficava eufórica, vomitava, andava tronxa, visão dupla, esquecimento que tenho até hoje. Nunca tive acompanhamento por profissionais. Ficava alterada, valente, ansiosa, chorava demais quando bebia. Eu bebia a custa dos outros. Brigava nos bares. Quando a gente bebe, as pessoas não querem saber da gente. Eu parei de beber, porque meu esposo morreu $e$ não bebi mais. Nunca tive recaída. (Orquidea)

Provei com 12 anos, em casa, mas com 17 que comecei a beber para me embriagar. Começou uma vez no mês e foi aumentando para toda semana. (Azaléa)

Iniciei em casa com minha família com 15 anos a bebida, em 1995. No começo bebia pouco, mas com os anos perdi o controle. Bebi pela primeira vez com a mãe que bebia e colocava a bebida para mim também. Eu gostei do gole, do sabor da cerveja. Ninguém me forçou. Bebia mais no final de semana, mas depois fui bebendo 3,4 dias sem parar. Passei até 15 dias bebendo direto sem vim para casa. Bebia com colegas, nos bares, na casa de alguém. Na família, bebia menos para não ter confusão. Gostava mais de cerveja e montilla. Bebia mais de 6 copos. Bebia nos três horários, sem hora para parar. Ficava eufórica, as vezes com sono. Dormia na calçada. (Violeta)

Comecei a beber para me embriagar aos 17 anos, porque em casa não podia entrar bebida. Bebia mais nas festas Começou uma vez no mês $e$ foi aumentando para toda semana. (Tulipa)

Comecei a beber com 12 anos e já não conseguia parar. Eu tinha ressaca e bebia para tirar a ressaca. Ficava eufórica, com visão embaçada, andar de embriagada, vomitava, tinha esquecimento (apagamento). Fiz muito isso. Não me alimentava e ia direto para o álcool. (Gerbera)

\section{Uma das entrevistadas iniciou o} consumo de álcool na fase adulta.

Comecei a beber com 40 anos. Eu era viúva, morava em São Paulo e vim morar aqui com meus pais. Tenho dois filhos. Com o tempo, já com meus filhos crescendo comecei a beber socialmente. De início em festas, com amigos e familiares $e$ depois, sozinha em casa. No final, bebia todos os dias. Antes disso não bebia. Bebia para resolver os problemas. Não gostava do sabor, só 
queria o efeito para esquecer as coisas. Gostava mais de cachaça, pois tinha efeito mais rápido e era mais fácil de esconder dos meus familiares. Bebia mais à noite até ficar embriagada. Ficava eufórica que todo mundo notava logo. Perdia o equilíbrio e tentava disfarçar. Não usei droga associada. Tinha esquecimento. Sem familiares. Fui para psicólogo... ele me aconselhava. Fiquei hipertensa por causa do álcool. (Alfazema)

O alcoolista perde o controle sobre sua vontade, depois o respeito pelos outros, a memória, o raciocínio abstrato, a capacidade de concentração, o trabalho e esses aspectos interferem negativamente na dinâmica familiar, e muitos chegam a perder a própria vida, em acidentes, doenças físicas, homicídios ou suicídios. A primeira condição para se livrar do alcoolismo é ficar abstêmio. 0 adicto pode procurar auxílio de organizações de ajuda mútua, tais como os $A A$, nos quais os dependentes encorajam uns aos outros a se manterem sóbrios numa metodologia de ajuda mútua $26,28,29$.

Os locais mais referidos para o início do hábito foram em casa com a família, sozinha ou com amigos, em festa ou evento social. Considerando a variável motivo para início do uso do álcool, constatou-se que a maioria iniciou o consumo para acompanhar o grupo em que estava inserida, por que estava nervosa ou tinha problemas, porque gostava do sabor da bebida e por outros motivos pessoais. Ingeriam bebidas alcoólicas mais de uma vez por dia, uma vez por semana. Casos de etilismo na família foram apontados pela maioria das entrevistadas.

Muitas situações indicava que eu deveria parar de beber, mas não me reconhecia como alcoolista". Quando parei de beber, pude ajudar a cuidar da minha mãe que estava muito doente. Certo, dia vieram me perguntar sobre uma pessoa que iria para o AA. Nesse momento, me ofereci para ir ao grupo. Não tive recaída. Parei definitivamente há 21 anos. (Margarida)

Eu não sabia como parar. Todos me criticavam. Bebia escondido. Me sentia mal porque bebia. Fui socorrida, mas continuei bebendo. Eu bebia para curar a ressaca. (Gérbera)

A pessoa consumidora de bebida alcoólica, assim como sua família, também, na maioria das vezes, não se reconhece como doente/dependente, até por não considerar o alcoolismo uma doença. Muitas vezes pelo sofrimento, vergonha, medo do estigma, buscam ocultar essa situação, dificultando o tratamento e a reintegração da pessoa na sociedade. Apesar das facilidades de acesso aos grupos de apoio, a estigmatização do uso de álcool apresenta uma considerável barreira aos 
esforços dos profissionais da saúde em realizar o tratamento ${ }^{7}$.

As bebidas de maior consumo foram cerveja e aguardente numa quantidade de dois a seis copos/dia, sem horário predeterminado, ou seja, consumiam durante todo o dia. Apenas uma entrevistada afirmou que bebia exclusivamente no período noturno. Constatou-se, também, a associação com outras drogas.

Ah, eu usava outras coisas... Meus amigos levavam cocaína para a gente. Eu usava apenas para não dormir por que queria continuar bebendo. Eu não queria parar ne? Eu tinha muito prazer em beber, eu gostava do sabor da bebida... era muito bom. (Tulipa)

Usei crack. Quando bebia, eu procurava, mas boa não saía de casa. Transei com algumas pessoas sem lembrar por causa da bebida. Brigava muito quando bebia. Quando estava boa, ficava com medo de ter feito alguma coisa. Trocava o trabalho para beber. Marcava para fazer o serviço e não ia, porque preferia ficar bebendo. Minha filha tinha medo quando eu bebia, porque queria bater nela. Eu não me lembrava que fazia isso. Minha mãe disse que se eu não parasse de beber, não fosse na casa dela. Procurava qualquer canto para dormir na rua. (Alfazema)

Constatou-se, que a mulher independente da condição social no qual esteja inserida é repreendida. Observouse que a maioria das mulheres entrevistadas iniciou o uso abusivo de bebidas alcoólicas entre 12 e 16 anos de idade. Esses dados são semelhantes aos encontrados em outras fontes pesquisadas nas quais mostram que muitas mulheres começam a fazer uso de álcool precocemente, ainda na adolescência. Muitas iniciam a ingesta alcoólica nessa fase da vida com o intuito de vivenciar situações prazerosas, evitar o desprazer, ou ainda, em busca de auto afirmação 20,23,30.

Essas mulheres passaram por diversas experiências, as quais traziam a marca da solidão, da dor, do sofrimento, da vergonha e da discriminação e vivenciaram perdas, agravos físicos e psicológicos decorrentes do uso abusivo de álcool. Além desses motivos, algumas relataram que iniciaram o uso do álcool por gostar do sabor da bebida.

As mulheres relataram as sensações durante o consumo do álcool como: euforia, alterações visuais, alterações motoras, sonolência e vômitos. Todas relataram lapso de memória após o uso da bebida.

Quando questionadas sobre transtornos mentais e comportamentais, a maioria relatou a presença de algum tipo de alteração, seja fóbico-ansioso, afetivo-bipolar e depressão. A comorbidade mais associada uso nocivo do álcool foi o transtorno afetivo bipolar. 
Foram consensuais, também, em afirmar que sofriam de ansiedade. As mulheres alcoólicas sofrem riscos de desenvolver doenças cardiovasculares, câncer da mama, osteoporose e distúrbios psiquiátricos, entre outros 8,17 .

Eu acredito que a dificuldade das mulheres não é a acessibilidade, porque o AA é muito acessivel. A dificuldade financeira, amorosa, a instabilidade emocional é muito propícia para você buscar algo. Assim como qualquer vício, o álcool the proporciona a fuga para você se desligar de qualquer problema. Quando você se torna alcóolatra, você termina procurando motivos para beber, seja por alegria ou tristeza. Quando você está bem, sempre acha que falta algo que é exatamente o vício. (Rosa)

Quanto às comorbidades clínicas, constatou-se que o aparelho digestivo foi o mais atingido, pois a maioria referia ter gastrite, úlcera, cirrose hepática. 0 fígado foi o principal órgão afetado pelo álcool. Existem basicamente três tipos de doenças do fígado determinadas pelo uso de álcool: esteatose (fígado gorduroso), hepatite alcoólica e cirrose alcoólica. Além do fígado, o álcool pode afetar outros órgãos do sistema gastrointestinal, tais como o pâncreas e o estômago. No pâncreas, o álcool é um dos principais fatores responsáveis pela pancreatite aguda e crônica
Eu sofria de gastrite, labirintite, depressão queria parar, mas não conseguia e entrei em depressão. (Órquidea)

0 registro de comorbidades psiquiátricas variou entre as entrevistadas, sendo que seis mulheres apresentaram transtornos mentais $\mathrm{e}$ comportamentais devidos ao uso de substâncias psicoativas. Todas referiram transtornos neurótico, fóbico-ansiosos, esquizofrênicos, depressão e hipertensão. Duas citaram episódios de transtornos afetivo-bipolar. O álcool é uma das substâncias que aumenta o risco de suicídio além de diversos prejuízos sociais.

Teve um dia que eu estava tão bêbada, que sai devagarzinho sem ninguém perceber e planejei de me jogar na frente dos carros ali na $B R$, sabe? Era uma hora de muita movimentação e eu queria que as pessoas pensassem que era um acidente. Ai uma amiga chegou na hora e me chamou, eu encontrei uma desculpa dizendo que ia fazer as unhas. (Alfazema)

0 registro de comorbidades sociais foram relatadas por todas as mulheres, sendo que o conflito com os filhos foram os que apareceram em maior frequência, seguidos de problemas no trabalho e agressões físicas, problemas conjugais, financeiros, 
problemas com amigos e por atos ilícitos ${ }^{2,6}$.

Meus filhos tinham vergonha de trazer alguma namorada em casa por que eu bebia. Eu só parei de beber por causa do sofrimento dos meus filhos. (Azaléa)

Eu só parei de beber quando percebi que meus filhos estavam ingressando na bebida, ai eu resolvi entrar no AA. Também tive muitas separações, quatro vezes. Isso foi piorando minha depressão. Dei parte na Delegacia da Mulher por que meu marido, que também era alcoólatra, me batia muito. (Margarida)

Estudos apontam que a dificuldade em exercer estas atividades devido ao consumo de substâncias gera sentimento de culpa e vergonha entre as mulheres $^{13}$, assim como observado em uma entrevista.

Tinha remorso por que bebia. Era uma sensação de desvalorização, de tristeza. Mas depois, eu voltava a repetir o erro. Eu não sentia arrependimento, por que sempre eu voltava a repetir o mesmo erro. Por isso procurei o AA para não beber mais, por que lá eu me sinto arrependida do que eu fazia e me sinto mais forte para evitar o primeiro gole. $O$ que poderia ter evitado se não bebesse? Poderia ter me formado, estudado mais. Não tenho medo de recaída. Hoje não sinto vontade de beber. (Tulipa)

O álcool é reconhecido como causa de complicações sociais ao longo de séculos, também é reconhecido como causa de complicações clínicas e psiquiátricas.

Tive muitos problemas com meus filhos que sofreram muito quando eu ingeria álcool, ficava agressiva, bati neles embriagada. Os poucos amigos que tenho contato me compreendem. As pessoas deixaram de me oferecer bebida. (Azaleia)

Além de contribuir para o surgimento de doenças, o uso abusivo do álcool é responsável, também, por diversos atos de violência, pelos mais variados tipos de acidentes, no trânsito, no trabalho, na família.

Foi depois que vi uma violência. Um homem morreu com uma machadada na minha frente, aí resolvi me afastar, e me isolar, com medo de sair de casa... também percebi que meus filhos estavam ingressando na bebida, $o$ que foi piorando a depressão. Foi quando resolve entrar no $A A$. Meu marido me acompanhou. Ele pensava que o $A A$ só tinha gente bêbado. Ele já estava muito debilitado. Ele ingressou $e$ com 6 meses, ingressei, porque não acreditava mais que ele iria parar de beber. Ele estava inchando $e$ pensando que estava engordando. Participo dos serviços do $A A$ que ajudam a gente a ficar lá, porque tem o compromisso. Muitas separações, quatro vezes. Agressão do marido. Dei parte na delegacia da mulher, porque ele me batia. (Gérbera)

Apesar das suas consequências desastrosas, o ato de beber é considerado parte fundamental do convívio social, dificultando as 
campanhas de conscientização. No extremo do ato de beber, se encontra pessoas que fazem uso nocivo e os dependentes do álcool, que devem contar com o apoio e a compreensão da sociedade para sua recuperação, deixando $\mathrm{o}$ preconceito de lado $\mathrm{e}$ tratando-os, dignamente, com 0 merecido respeito.

Se eu não bebesse? Se eu tivesse conseguido evitar o álcool desde que meus filhos eram crianças, eles não beberiam como bebem hoje. Bebi desde eles crianças até eles se tornarem adultas e temo que eles passem pelos mesmos problemas que eu e meu marido passamos. Acidente de trânsito com meu marido de ressaca. A ressaca era pior... tinha dor de cabeça, ficava lenta. $O$ pessoal não conhece o $A A$. Precisamos de informações. (Rosa)

Apesar de ser crescente a abordagem acerca da temática do alcoolismo nas mulheres, observa-se que a visão da sociedade frente ao alcoolismo feminino é bastante preconceituosa. A mulher sofre com a estigmatização e seu comportamento é considerado imoral e inadequado. Assim, a procura por tratamentos em centros de ajuda como, por exemplo o AA ocorre com menor frequência do que pelos homens ${ }^{7}$.

A participação de mulheres em atividades sociais e de trabalho é considerada como fator de menor contribuição para o consumo do álcool. Entretanto, entre as mulheres entrevistadas foi encontrado uma variedade de atividades laborais, o que se traduz em um maior consumo de bebidas alcoólicas mesmo quando as mulheres tinham as suas atividades de lazer e sociais preservadas. Na pesquisa, isso foi reforçado, qualitativamente, a partir do relato de uma professora de ensino médio, cuja profissão a mantinha ocupada durante todos os dias da semana.

Quando chegava a sexta-feira, eu já me preparava para passar o final de semana virado ne? (Orquídea)

Muitas vezes, o álcool foi consumido em associação com outras substâncias psicotrópicas, como por exemplo o tabaco e a maconha, embora também foi referido a associação álcoolmedicamentos.

Efeitos da ressaca foram os problemas que tive, mas nada diagnosticado como consequência do álcool. Acredito que tive gastrite, mas não procurei ajuda médica. Sempre tive gripes fortes, mas não tuberculose. Tive relações com pessoas no álcool sem lembrar. Já usei cocaína associada ao álcool para não dormir e consumir mais álcool. Tinha alteração comportamental visível. Depressão. Eu achava que era passageiro, foi quando procurei o AA por iniciativa própria. Eu me reconheci como 
alcoolista e decidi procurar ajuda quando minha mãe disse que ia sair de casa, porque não aguentava mais. Eram recaídas instantâneas. Meu marido bebia muito e tivemos muitos problemas. (Margarida)

Se não tivesse bebido teria terminado meus estudos. Nunca trabalhei, porque escolhi a bebida. As vergonhas que fiz minha filha $e$ minha família passar. Eu não ligava para nada, só queria saber das bebidas mesmo. Tenho medo de ter recaídas. Evito os ambientes, as velhas amizades. Nunca ganhei nada com bebida, só traz desgraça. (Alfazema)

A literatura mostra que 0 alcoolismo apresenta sintomas graves, que persistem ao longo do tempo, provocando comorbidades que podem comprometer todo 0 organismo4,5,7,11,22,29. Além disso, tem implicações físicas, psicológicas, sociais, profissionais e familiares, logo o tratamento, para que tenha sucesso, deverá ser multidisciplinar e realizado a longo prazo.

\section{CONSIDERAÇÕES FINAIS}

A partir dos dados apresentados, constata-se a relevância do tema em questão e a necessidade de realização de estudos voltados ao levantamento, à prevenção, ao tratamento e à redução dos danos a que estão expostas as usuárias de álcool, especialmente, aos desfechos relacionados a este segmento da população.

Torna-se notório com esses achados o impacto e a degradação que o álcool provoca na vida dessas usuárias, além de trazer prejuízos, muitas vezes, irreparáveis a sua própria saúde e a saúde daqueles com quem convivem. 0 reconhecimento de tais mulheres tornase de extrema relevância, pois fornece subsídios para aperfeiçoar o atendimento/acolhimento/assistência, melhorar a aderência destas pacientes ao tratamento, o que permitiria que as ações saúde que possuem maior alcance.

Nessa pesquisa, o consumo abusivo de álcool não está relacionado a características específicas do grupo estudado, ou seja, esse fato independende da classe social, etnia/raça, escolaridade ou outra variável sociodemográfica, constatando que esta questão trata-se de problemática ainda mais abrangente.

Conclui-se pela necessidade e importância de estudos dessa natureza que possam contribuir para o conhecimento do problema subsidiando intervenções futuras. Os resultados da pesquisa revelaram que há violência sofrida pelas mulheres, principalmente, no ambiente doméstico no âmbito do consumo de álcool. 
Conhecer o padrão de uso do álcool por esse segmento da população favorece 0 planejamento de intervenções terapêuticas e estratégias preventivas mais precisas que visem a reduzir os riscos do beber problemático. Assim sendo, a comunidade científica carece de estudos metodologicamente refinados a respeito das famílias e dos usuários dessas substâncias, de uma maneira geral, e do papel que desempenham na superação do estado clínico de abstinência. Conhecer o perfil dessas pessoas é de suma importância, a fim de sinalizar estratégias e planejamento para atendimento global frente às especificidades apresentadas.

Com relação às limitações do estudo, pode-se afirmar que foram analisadas apenas oito entrevistas de um grupo de vinte mulheres alcoólicas anônimas da cidade de Mossoró. 0 tamanho da amostra é reduzido devido à falta de consentimento das demais participantes do grupo. Além disso, o grupo apenas se reunia no período noturno, o que dificultou o acesso às reuniões. Deste modo, recomendam-se estudos futuros em outros contextos, afim de aprofundar o conhecimento sobre a temática.

\section{REFERÊNCIAS}

1. Ministério da Saúde (BR). Portaria $n .^{\circ}$ 130, de 26 de Janeiro de 2012. Disponível em:

http: / /bvsms.saude.gov.br. Acessado em 08/03/2018.

2. Organização Mundial da Saúde. Relatório Global sobre Álcool e Saúde2014.Genebra: Suíça; 2014. Disponível em:

http://www.cisa.org.br/artigo/4429/r elatorio-global-sobre-alcool-saude2014.php . Acessado em 09/03/2018.

3. Laranjeira R, Madruga CS, Pinsky I, Caetano R, Mitsuhiro SS. II Levantamento Nacional de Álcool e Drogas. São Paulo: Instituto Nacional de Ciência e Tecnologia para Políticas Públicas de Álcool e Outras Drogas (INPAD) - UNIFESP; 2014.

4. Souza LGS, Menandro MCS, Menandro PRM. O alcoolismo, suas causas e tratamento nas representações sociais de profissionais de Saúde da Família. Physis (Rio J). 2015; 25(4):1335-60.

5. Esper LH, Corradi-Webster CM, Carvalho AMP, Furtado EF. Women in outpatient treatment for alcohol abuse: sociodemographic and clinical characteristics. Rev gaúch enferm. 2013; 34(2):93-101. 
6. Mangueira SO, Guimarães

FJ, Mangueira

JO, Fernandes

AFC, Lopes MVO. Promoçao da saúde

e políticas públicas do álcool no

Brasil: Revisão Integrativa da

literatura. Psicol soc. 2015; 27(1):157-

68.

7. Guimarães ACB, Mahfoud $M$. Experiência comunitária e realização pessoal em Alcoólicos Anônimos: uma pesquisa fenomenológica. SMAD, rev eletrônica saúde mental álcool drog. 2016; 12(4):231-9.

8. Vargas D, Soares J, Leon E, Pereira CF, Ponce TD. O primeiro contato com as drogas: análise do prontuário de mulheres atendidas em um serviço especializado. Saúde debate. 2015; 39(106):782-91.

9. Popova S, Lange S, Burd L, Chudley AE, Clarren SK, Rehm J. Cost of fetal alcohol spectrum disorder. 2015. 41, 76-81. Disponível em: https://app.dimensions. ai/details/pu blication/pub. Acesso em 03 de set de 2018.

10. Costa ACPJ, Silva PM, Rocha PC, Araújo MFM, Araújo TM, Vieira NFC. Alcoolismo materno e as implicações no cuidado da criança: estudo qualitativo. SMAD, rev eletrônica saúde mental álcool drog. 2014; 10(3):151-83.
11. Motta KMC, Linhares MBM. Perfil das gestantes usuárias de álcool/drogas e o efeito na saúde e desenvolvimento dos filhos. Inter psicol. 2015; 19(1):133-44.

12. Oliveira AM, Santos AJRB, Alvarez FTLC, Enokibara MP, Medeiros MF. Estudo das percepções de mulheres em idade fértil sobre os efeitos da ingestão de bebidas alcoólicas durante a gravidez como proposta para sistematização de práticas de ensino pela enfermagem para a prevenção dos transtornos do espectro alcoólico fetal. Rev pesqui cuid fundam. 2016; 8(1):3860-72.

13. Esper LH, Corradi-Webster CM, Carvalho AMP, Furtado EF, Gomes RSV, Zerbettob SR. Padrão do uso de álcool por usuários de uma Unidade de Saúde da Família. Cad ter ocup UFSCar. 2014; 22(supl esp):27-35.

14. Monteiro CFS, Dourado GOL, Graça Júnior CAG, Freire AKN. Relatos de mulheres em uso prejudicial de bebidas alcoólicas. Esc Anna Neri. $2011 ; 15(3): 567-72$.

15. Lucena-Santos P, Araujo RB. Tratamento CognitivoComportamental sinérgico de dependência química, bulimia 
nervosa e transtorno bipolar. Psicol argum. 2015; 33(83):496-510.

16. Silva MGB, Lyra TM. O beber feminino: socialização e solidão. Saúde debate. 2015; 39(106):772-81.

17. Esper LH, Corradi-Webster CM, Carvalho AMP, Furtado EF. Mulheres em tratamento ambulatorial por abuso de álcool: características sociodemográficas e clínicas. Rev gaúch enferm. 2013; 34(2):93-101.

18. Pillon SC, Santos MA, Florido LM, Cafer JR, Ferreira PS, Scherer ZAP, et al. Consequências do uso de álcool em mulheres atendidas em um Centro de Atenção Psicossocial. Rev eletrônica enferm. 2014; 16(2):33845.

19. Ponce TD. O primeiro contato com as drogas: análise do prontuário de mulheres atendidas em um serviço especializado. Saúde debate. 2015; 39(106):782-91.

20. Oliveira GC, Dell'Agnolo CM, Ballani TSL, Carvalho MDB, Pelloso SM. Consumo abusivo de álcool em mulheres. Rev gaúch enferm. 2012; $33(2): 60-8$.

21. Valentim OS, Santos C, Pais-Ribeiro J. Vulnerabilidade ao Stress em Pessoas com Alcoolismo. Rev port enferm saúde mental. 2015; (spe2):57-62.
22. Vieira LB, Cortes LFS, Padoin SM, Souza IMO, Paula CC, Terra MG. Abuso de álcool e drogas e violência contra as mulheres: denúncias de vividos. Rev bras enferm. 2014; 67(3):366-72.

23. Garrido MCT, Pinho SR, Aguiar WM, Dunningham WA. Prevalência de alcoolismo e sintomas depressivos em pacientes da clínica geral na cidade de Salvador-BA. Rev bras neur psiq. 2016; 20(1):37-72.

24. Vieira S, Hossne SW. Metodologia científica para a área da saúde. Rio de Janeiro: Campus; 2001.

25. Moraes LF. Álcool, gravidez e síndrome alcoólica fetal: uma proposta de educação em saúde. Rev bras educ saúde. 2014; 5(1):1-8.

26. Alzuguir FV. A carreira moral da vergonha na visão de homens e mulheres alcoólatras.Physis (Rio J). 2014; 24(1):11-29.

27. Wilsnack SC, Wilsnack RW, KANTOR LAW. Focus on: Women and the costs of alcohol use. Alcohol Research: Current Reviews. 2013; 35(2):219-28.

28. Santos AM, Silva MR. A experiência de cuidar da mulher alcoolista na família. Rev esc enferm USP. 2012; 46(2):364-71.

29. Pillon SC, Santos MA, Florido LM, Cafer JR, Ferreira PS, Scherer ZAP, 
et al. Consequências do uso de álcool em mulheres atendidas em um Centro de Atenção Psicossocial. Rev eletrônica enferm. 2014; 16(2):33845.
30. Nascimento VF, Moll MF, Lemes AG, Cabral JF, Cardoso TP, Luis MAV. Percepción de las mujeres en situación de dependencia química dentro de Mato Grosso, Brasil. Cult cuid. $2017 ; 21(48): 33-42$.

Conflito de interesses: Os autores declaram não haver conflito de interesses.

\section{Participação dos autores:}

- Concepção: Luna BPLS, Silva Júnior GL, Pereira ISSD.

- Desenvolvimento: Luna BPLS, Silva Júnior GL, Pereira ISSD.

- Redação e revisão: Luna BPLS, Silva Júnior GL, Pereira ISSD.

Como citar este artigo: Luna BPLS, Silva Júnior GL, Pereira ISSD. Alcoolismo e comorbidades em mulheres. J Health NPEPS. 2019; 4(1):62-79. 